\title{
Reliability analysis of a gravity-based foundation for wind turbines: a code-based design assessment
}

\author{
M. J. VAHDATIRAD*, D. V. GRIFFITHS $\uparrow+$, L. V. ANDERSEN*, J. D. SøRENSEN* and G. A. FENTON§
}

\begin{abstract}
Deterministic code-based designs proposed for wind turbine foundations are typically biased on the conservative side, and overestimate the probability of failure, which can lead to higher than necessary construction cost. In this study reliability analysis of a gravity-based foundation, concerning its bearing capacity, is used to calibrate a code-based design procedure. A probabilistic finite-element model is developed to analyse the bearing capacity of a surface footing on soil with spatially variable undrained strength. Monte Carlo simulation is combined with a re-sampling simulation technique to perform the reliability analysis. The calibrated code-based design approach leads to savings of up to $20 \%$ in the concrete foundation volume, depending on the target annual reliability level. The study can form the basis for future optimisation on deterministic-based designs for wind turbine foundations.
\end{abstract}

KEYWORDS: bearing capacity; finite-element modelling; footings/foundations; offshore engineering; statistical analysis

\section{INTRODUCTION}

Gravity-based foundations are regularly used for on- and offshore wind turbine structures. Expenses related to gravitytype foundations account for roughly $20-25 \%$ of the total budget for an offshore wind farm (Nilsen, 2003; European Wind Energy Association, 2009) and current deterministic, code-based designs are quite conservative in most situations (Vahdatirad et al., 2013). In the design process, expensive measurements are performed in situ at each wind turbine. The soil is considered to be a locally homogeneous material within each detected layer and representative distributions for the strength parameters are estimated from the measurements; the characteristic values are chosen as conservative values which correspond to $5 \%$ quantiles (DNV, 2013).

However, a realistic design should deal with several uncertainties due to material properties, measurement techniques and/or modelling procedures. Furthermore, the soil is a heterogeneous material, and failure mechanisms in heterogeneous and homogeneous materials can be markedly different. Uncertainties are usually not accounted for or are conservatively neglected by the inclusion of some partial safety factors and quantile values in deterministic code-based designs. As a result, a conservative design is provided leading to a higher reliability level, thus causing unnecessarily high construction costs. This overestimation implies bias in the deterministic design or standards-based design equation. To account for the bias and uncertainties in these equations, a probabilistic model accounting for the uncer-

Manuscript received 1 September 2013; revised manuscript accepted 19 May 2014. Published online ahead of print 10 July 2014.

Discussion on this paper closes on 1 January 2015, for further details see p. ii.

* Department of Civil Engineering, Aalborg University, Aalborg, Denmark.

$\dagger$ Department of Civil and Environmental Engineering, Colorado School of Mines, Golden, CO, USA.

$\$$ Australian Research Council Centre of Excellence for Geotechnical Science and Engineering, University of Newcastle, Callaghan, NSW, Australia.

$\S$ Department of Engineering Mathematics, Dalhousie University, Nova Scotia, Canada.

This paper is subject to British Crown Copyright. tainties can be developed. This model can be used through a reliability analysis to calibrate the design equation and the partial safety factors, including possible biases.

Several studies have been conducted on probabilistic models, either for general foundations or wind turbine foundations specifically. Among the probabilistic models for general foundation issues, Griffiths \& Fenton (2000, 2001) developed the random finite-element model (RFEM) to investigate the bearing capacity of undrained clays with spatially varying shear strength. They performed sensitivity analyses to illustrate the importance of variance and spatial correlation length of the soil's undrained shear strength, and to demonstrate how they impact the statistics of the bearing capacity.

Popescu et al. (2005) studied the effects of random heterogeneity of soil undrained shear strength on bearing capacity. They considered spatial variability and undrained shear strength mean value as two major sources of uncertainties and conducted a non-linear finite-element (FE) analysis in conjunction with Monte Carlo simulation (MCS). Griffiths et al. (2002) performed a parametric study of the bearing capacity of a rough, rigid strip footing on weightless cohesive soil using RFEM. They investigated the effect of the spatial variation of cohesion on the mean bearing capacity and compared rough and smooth footing conditions. In a similar study, Griffiths et al. (2006) studied a probabilistic model using RFEM at the interface of two parallel rigid strip footings on weightless cohesive soil with randomly distributed undrained shear strength.

To estimate the bearing capacity of a strip footing on weightless soil, Paice \& Griffiths (1999) performed a reliability analysis of the bearing capacity of an undrained clay block having spatially random properties, whereas Fenton \& Griffiths (2003) analysed a two-dimensional (2D) RFEM and derived a theoretical prediction of the bearing capacity, which they verified by MCS. Fenton et al. (2007) developed a code-based theoretical model to predict the probability of failure for the bearing capacity of a shallow foundation. They verified the theoretical model using 2D RFEM and proposed it for developing resistance factors for use in code provisions. In another study, Fenton et al. (2008) assessed the load resistance factor design approach for the bearing 
capacity of a strip footing, using load factors as proposed by structural codes. Resistance factors were calibrated to achieve an acceptable target probability of failure. Cassidy et al. (2013) identified probabilistic failure envelopes of a strip footing under combined loading. The Abaqus finiteelement package (Dassault Systèmes Simulia Corp, 2012) was used for the stochastic FE modelling with spatially variable undrained shear strength. The RFEM used in studies for bearing capacity problems was also adopted for use in foundation settlement issues, and its efficiency was evaluated (see, e.g. Fenton et al., 2005; Fenton \& Griffiths, 2005; Phoon, 2008; Griffiths \& Fenton, 2009).

In association with specific studies on the probabilistic analysis for wind turbine foundations, Andersen et al. (2011) developed a probabilistic finite-difference model to estimate the stiffness of an offshore wind turbine mounted on a monopile foundation in clay. They used a lognormally distributed random field for the shear strength of undrained soil. In a similar study, Andersen et al. (2012) proposed an advanced reliability method to predict the low-probability events for the natural frequency of an offshore wind turbine founded on a monopile. Vahdatirad et al. (2011) studied the dynamic stiffness of a surface footing for offshore wind turbines on elastic soil. Elastic properties and soil depth were treated as random variables with lognormal distributions. The authors found that the stiffness of the footing was lognormally distributed. Vahdatirad et al. (2014) investigated the efficiency of an advanced reliability method for use in the probabilistic analysis of offshore foundations, using MCS as the benchmark for assessments. Vahdatirad et al. (2013) developed a probabilistic three-dimensional (3D) FE model for an offshore monopile foundation. They considered a spatially random field for the soil's undrained shear strength and mapped random properties at each integration point of the soil elements. The Abaqus numerical package was used by way of scripting in the Python interface to solve the probabilistic FE problem. A reliability analysis was performed to investigate the failure probability at serviceability and ultimate limit states.

Given that usually a conservative design is obtained using a deterministic, code-based design, there is room for calibrating the design equations. The main contribution of this study is the development of a framework for a deterministic, code-based design using an acceptable reliability level for the failure mode that the foundation will exceed its supporting soil-bearing capacity. A deterministic design is performed against the bearing failure of a gravity-based foundation, according to the offshore standard (DNV, 2013). However, the use of inclination factors and effective area method, as assumed in this paper, are being replaced with equations that write capacity directly in terms of the vertical-horizontal-moment loading conditions (Randolph et al., 2004). The strength of the paper is the motivation to calibrate against a design guideline. The results are used to create and calibrate an FE model representing the codebased design. A stochastic FE model based on probabilistic modelling in the Abaqus numerical package, as proposed by Vahdatirad et al. (2013), is used in this study. The foundation is considered to be on cohesive soil with spatially varying undrained shear strength. Reliability analysis is performed with a re-sampling simulation technique (Efron \& Tibshirani, 1993) to model the uncertainty of the bearing capacity. Reliability levels for the DNV code-based design are relatively high, indicating the presence of biases in the deterministic design, which are assessed for the resistance part of the design equation.

\section{DETERMINISTIC DESIGN}

A gravity-based foundation for a wind turbine is designed against bearing failure using the DNV standard (DNV, 2013). The foundation is designed with the properties shown in Table 1, for the loads given in Table 2 (Sørensen, 2013) and for the soil conditions listed in Table 3 . The value obtained for the effective foundation width, $b_{\text {eff }}$, defined as the width of the foundation-soil interface under pressure, was used to construct the FE model.

\section{DNV approach}

According to DNV, an effective area, $A_{\text {eff }}$, is needed to determine the bearing capacity. This area closely follows the nearest corner of the true area of the foundation base, and its geometrical centre coincides with the centre of the applied load. Fig. 1 illustrates the effective area for a circular and an octagonal foundation (DNV, 2013). The elliptical effective area in Fig. 1 can be calculated as

$$
A_{\text {eff }}=2\left[R^{2} \arccos \left(\frac{e}{R}\right)-e \sqrt{R^{2}-e^{2}}\right]
$$

where $R$ is the foundation radius and $e=M / V$ is the load eccentricity with bending moment $M(\mathrm{kNm})$ and vertical load $V(\mathrm{kN})$.

To use the effective area in the classical bearing capacity equation, $A_{\text {eff }}$ is represented by a rectangle (Fig. 1) with an effective width $b_{\text {eff }}$ and effective length $l_{\text {eff }}$, given in equation (2) and equation (3), respectively

$$
b_{\text {eff }}=\sqrt{\frac{A_{\text {eff }}(R-e)}{\sqrt{R^{2}-e^{2}}}}
$$

Table 1. Wind turbine properties

\begin{tabular}{l|c}
\hline Property & Value \\
\hline Rotor weight & $540 \mathrm{kN}$ \\
Nacelle weight & $820 \mathrm{kN}$ \\
Tower weight & $2050 \mathrm{kN}$ \\
Transition part weight & $590 \mathrm{kN}$ \\
Height from foundation base & $85 \mathrm{~m}$ \\
\hline
\end{tabular}

Table 2. Load conditions at the foundation base (distribution and COV data from Sørensen (2013))

\begin{tabular}{l|l|c|c|c}
\hline Load type at the foundation base & Distribution & Mean & COV & Quantile \\
\hline Horizontal, $H: \mathrm{kN}$ & Weibull & 1000 & $0 \cdot 15$ & $98 \%$ \\
Moment, $M=H L: \mathrm{kN} \mathrm{m}$ & Weibull & $1000 \times 85$ & $0 \cdot 15$ & $98 \%$ \\
Vertical, $V: \mathrm{kN}$ & - & $4000+28 \pi R^{2 \dagger}$ & - & - \\
\hline
\end{tabular}

${ }^{*} L=85 \mathrm{~m}$ is the height of wind turbine, see Table 1 . Therefore, $M$ and $H$ are fully correlated.

$\dagger$ The vertical load is a function of foundation radius, $R(\mathrm{~m})$, and weight of the wind turbine. Rough values of $2 \mathrm{~m}$ for the foundation height and $14 \mathrm{kN} / \mathrm{m}^{3}$ for the foundation submerged unit weight are considered. 
Table 3. Soil properties

\begin{tabular}{|c|c|c|c|c|c|c|c|}
\hline $\begin{array}{l}\text { Deterministic property } \\
\text { Friction angle: degrees } \\
\text { Dilation angle: degrees } \\
\text { Poisson ratio }\end{array}$ & \multicolumn{7}{|c|}{$\begin{array}{l}\text { Value } \\
0 \cdot 00 \\
0 \cdot 00 \\
0 \cdot 49\end{array}$} \\
\hline Stochastic property & Distribution & $\begin{array}{c}\text { Mean (JCSS, } \\
\text { 2006; Lee et } \\
\text { al., 1983) }\end{array}$ & $\begin{array}{l}\text { COV (JCSS, } \\
\text { 2006; Lee } \text { et } \\
\text { al., 1983) }\end{array}$ & $\begin{array}{c}\text { Quantile } \\
(\mathrm{DNV}, 2013)\end{array}$ & $\begin{array}{l}\text { Horizontal correlation length, } \\
\delta_{x}(\mathrm{~m}), \text { in terms of foundation } \\
\text { effective width, } b_{\text {eff }}\end{array}$ & $\begin{array}{c}\text { Vertical } \\
\text { correlation } \\
\text { length, } \delta_{y}: \mathrm{m}\end{array}$ & $\begin{array}{c}\text { Cross } \\
\text { correlation, } \\
\rho\end{array}$ \\
\hline $\begin{array}{l}\text { Undrained shear strength } \\
\text { for DNV method, } c_{\mathrm{u}} \text { : } \\
\mathrm{kN} / \mathrm{m}^{2} \\
\text { Undrained shear strength } \\
\text { for FEM, } c_{\mathrm{uFEM}}: \mathrm{kN} / \mathrm{m}^{2} \\
\text { Elastic modulus: } \mathrm{kN} / \mathrm{m}^{2}\end{array}$ & $\begin{array}{l}\text { Lognormal } \\
\text { Lognormal } \\
\text { Lognormal }\end{array}$ & $\begin{array}{r}111 \cdot 35 \\
20297 \cdot 00\end{array}$ & $\begin{array}{l}0 \cdot 40 \\
0 \cdot 40\end{array}$ & $\begin{array}{l}5 \% \\
5 \%\end{array}$ & $\begin{array}{l}\left\{0 \cdot 5 b_{\text {eff }}, b_{\text {eff }}, 2 b_{\text {eff }}, 4 b_{\text {eff }}, 8 b_{\text {eff }}\right\} \\
\left\{0 \cdot 5 b_{\text {eff }}, b_{\text {eff }}, 2 b_{\text {eff }}, 4 b_{\text {eff }}, 8 b_{\text {eff }}\right\}\end{array}$ & $\begin{array}{l}1 \cdot 00 \\
1 \cdot 00\end{array}$ & 0.90 \\
\hline
\end{tabular}

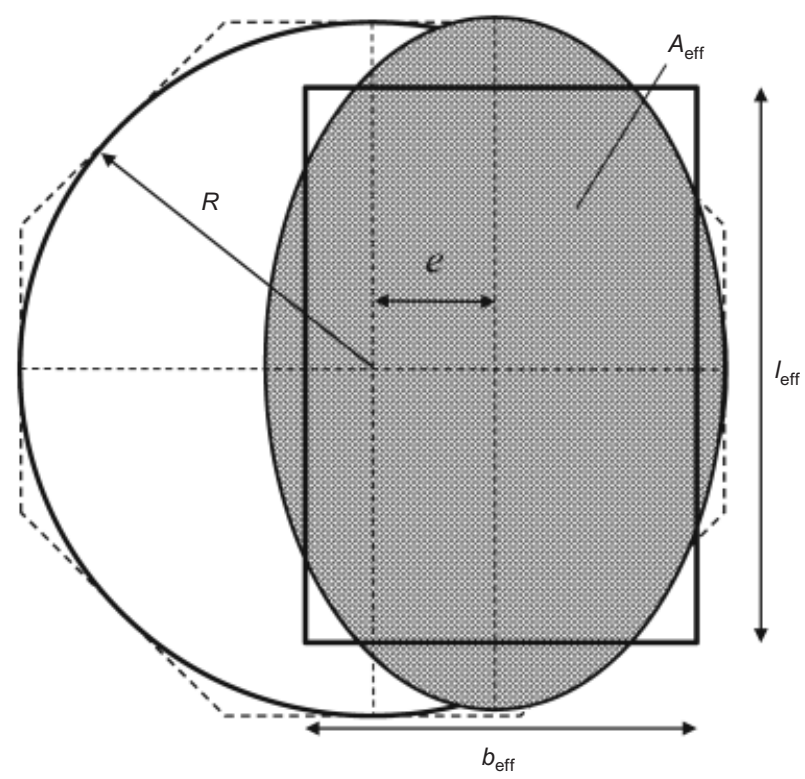

Fig. 1. Effective area for bearing capacity calculation in circular and octagonal foundation (after DNV, 2013)

$$
l_{\mathrm{eff}}=\sqrt{\frac{A_{\mathrm{eff}} \sqrt{R^{2}-e^{2}}}{R-e}}
$$

The bearing capacity of a gravity-based foundation for undrained conditions can be determined from equation (4)

$$
\begin{aligned}
& q_{\mathrm{u}}=c_{\mathrm{u}} N_{c}^{0} s_{c}^{0} i_{c}^{0}+p_{0} \\
& N_{c}^{0}=\pi+2 \\
& s_{c}^{0}=1+0 \cdot 2 \frac{b_{\mathrm{eff}}}{l_{\mathrm{eff}}} \\
& i_{c}^{0}=0 \cdot 5+0 \cdot 5 \sqrt{1-\frac{H}{A_{\mathrm{eff}} c_{\mathrm{u}}}}
\end{aligned}
$$

where $c_{\mathrm{u}}\left(\mathrm{kN} / \mathrm{m}^{2}\right)$ is the undrained shear strength at the depth of the potential failure surface, $N_{c}^{0}$ is the bearing capacity factor, $s_{c}^{0}$ is the shape factor, $i_{c}^{0}$ is the inclination factor, $H(\mathrm{kN})$ is the horizontal force at the foundation base and $p_{0}=0$ is the effective overburden pressure. Substituting all parameters into equation (4a) based on $c_{\mathrm{u}}, R, H, M$ and $V$, the bearing capacity is given by

$$
\begin{aligned}
q_{\mathrm{u}}= & c_{\mathrm{u}}(\pi+2)\left(1+0 \cdot 2 \frac{R V-M}{\sqrt{R^{2} V^{2}-M^{2}}}\right) \\
& \{0 \cdot 5+0 \cdot 5 \\
& \left.\times \sqrt{1-\frac{H}{2\left[R^{2} \arccos \left(\frac{M}{R V}\right)-\frac{M}{V} \sqrt{R^{2} V^{2}-M^{2}}\right]} c_{\mathrm{u}}}\right\}
\end{aligned}
$$

In the case of loading with an extremely high eccentricity, an additional bearing capacity failure mode should be checked. This checking is for a failure mode that involves failure of the soil under the unloaded area of the foundation. For example, this is the area under the heel of the foundation. In this case, the load inclination factor, $i_{c}^{0}$, is changed and a factor of $1.05+\tan ^{3} \phi$ is multiplied with the bearing capacity formula in equation (4a). For the undrained case $(\phi=0)$, the capacity is given by

$$
q_{\mathrm{u}}=1 \cdot 05 c_{\mathrm{u}} N_{c}^{0} s_{c}^{0} \sqrt{0 \cdot 5+0 \cdot 5 \sqrt{1+\frac{H}{A_{\mathrm{eff}} c_{\mathrm{u}}}}}
$$

Substituting parameters based on $c_{\mathrm{u}}, R, H, M$ and $V$, equation (6) can be written as

$$
\begin{aligned}
& q_{\mathrm{u}}=1.05 c_{\mathrm{u}}(\pi+2)\left(1+0.2 \frac{R V-M}{\sqrt{R^{2} V^{2}-M^{2}}}\right) \\
& \sqrt{0.5+0.5 \sqrt{1+\frac{H}{2\left[R^{2} \arccos \left(\frac{M}{R V}\right)-\frac{M}{V} \sqrt{R^{2} V^{2}-M^{2}}\right] c_{\mathrm{u}}}}}
\end{aligned}
$$

The bearing capacity $q_{\mathrm{u}}$ should be taken as the smallest value from equation (5) and equation (7).

\section{Design equation}

To determine the required foundation radius $R$, a deterministic, code-based design equation is established according to the appropriate standard (see, e.g. IEC 61400-1, (IEC, 2005))

$$
Y_{\mathrm{d}}-\gamma_{\mathrm{f}} H_{\mathrm{c}} L=0
$$

where $\gamma_{\mathrm{f}}$ is the partial safety factor for the load, $H_{\mathrm{c}}$ is the 
characteristic value for the horizontal load $H$ from Table 2, $L=85 \mathrm{~m}$ is the height of the wind turbine from the foundation base and $Y_{\mathrm{d}}$ is the characteristic value for the resistance part, obtained from equation (9)

$$
Y_{\mathrm{d}}=\theta_{\mathrm{c}} q_{\mathrm{uc}} A_{\mathrm{eff}} e
$$

Here, $\theta_{\mathrm{c}}$ is the characteristic value of uncertainty related to the bearing capacity model (see Table 5), and $q_{\mathrm{uc}}$ is the characteristic value for the bearing capacity, determined by substituting the characteristic values for the parameters into the bearing capacity equations. The characteristic value of $c_{\mathrm{u}}$ is reduced by a factor of $1 / \gamma_{\mathrm{m}}$, where $\gamma_{\mathrm{m}}$ is the partial safety factor for the material (see Table 4).

For the load part, this study considers uncertainty related to the wind which is the dominant load, acting horizontally at the centre of the rotor, whereas the vertical force from self-weight is considered deterministic in as much as the wind turbines are horizontally loaded structures with accurate fabrication; that is, there is low variability in the weight and consequently in the vertical load. When the characteristic and deterministic values for the loads (see Table 2), increased by the factor of $\gamma_{\mathrm{f}}$, and the characteristic value for $c_{\mathrm{u}}$ (see Table 3 ), multiplied by $1 / \gamma_{\mathrm{m}}$, are substituted into equation (5) and equation (7), $q_{\mathrm{uc}}$ becomes two parametric equations in terms of the foundation radius $R$, which is considered to be the design parameter. By substituting $q_{\mathrm{uc}}$ into equation (8), two parametric design equations are obtained in terms of $R$. The foundation radius can be obtained by solving these design equations for $R$ and considering the minimum value of $q_{\mathrm{uc}}$ from equation (5) and equation (7). Table 6 illustrates the solution for the gravitybased foundation in the present study.

Table 4. Partial safety factors for the design equation (partly based on IEC (2005))

\begin{tabular}{l|l}
\hline Variable & Value \\
\hline Partial safety factor for load effect, $\gamma_{\mathrm{f}}$ & $1 \cdot 35$ \\
Partial safety factors for material properties, $\gamma_{\mathrm{m}}$ & $1 \cdot 3$ \\
\hline
\end{tabular}

Table 5. Stochastic models for physical, model and statistical uncertainties (IEC, 2005; Sørensen, 2013)

\begin{tabular}{l|l|c|c|l}
\hline Variable & Distribution & Mean & COV & Quantile \\
\hline$\theta$ & Lognormal & $1 \cdot 00$ & $0 \cdot 10$ & $5 \%$ \\
$X_{\text {dyn }}$ & Lognormal & $1 \cdot 00$ & $0 \cdot 05$ & Mean \\
$X_{\text {exp }}$ & Lognormal & $1 \cdot 00$ & $0 \cdot 20$ & Mean \\
$X_{\text {aero }}$ & Gumbel & $1 \cdot 00$ & $0 \cdot 10$ & Mean \\
$X_{\text {str }}$ & Lognormal & $1 \cdot 00$ & $0 \cdot 10$ & Mean \\
\hline
\end{tabular}

Table 6. Design values for the gravity-based foundation in the present study

\begin{tabular}{l|r}
\hline Parameter & \multicolumn{1}{|c}{ Value } \\
\hline Foundation radius, $R: \mathrm{m}$ & 11.59 \\
Load eccentricity, $e: \mathrm{m}$ & $6 \cdot 78$ \\
Effective area, $A_{\text {eff }}: \mathrm{m}^{2}$ & $126 \cdot 70$ \\
Effective width, $b_{\text {eff }}: \mathrm{m}$ & $8 \cdot 05$ \\
Characteristic bearing capacity, $q_{\mathrm{uc}}, \mathrm{DNV}: \mathrm{kN} / \mathrm{m}^{2}$ & $199 \cdot 62$ \\
Characteristic bearing capacity, $q_{\mathrm{uc}}, \mathrm{FE}: \mathrm{kN} / \mathrm{m}^{2}$ & $199 \cdot 69$ \\
\hline
\end{tabular}

\section{DETERMINISTIC AND PROBABILISTIC FINITE- ELEMENT MODELS}

To perform reliability analyses, a probabilistic FE model is created within the Abaqus numerical package using Python scripting. The model is calibrated such that the deterministic FE analysis provides the same characteristic bearing capacity as that obtained by the DNV method (i.e. the design equation is appropriately satisfied). For this reason, the characteristic value of the strength parameter, here the undrained shear strength, is slightly changed such that the same bearing capacity is obtained using the FE model. As a result, $c_{\mathrm{uFEM}}$ in Table 3 has the calibrated characteristic value (5\% quantile value of resistance distribution, see DNV (2013)). It is usually proposed in codes for engineering design to use a $5 \%$ quantile of the mean value distribution (e.g. BS EN 1997-1 (BSI, 2004)), and the 2D assumption may not be very accurate. However, in the present paper a direct comparison with the DNV (2013) approach has been the main consideration and the motivation for the present study is to examine the influence of soil variability; that is, the model uncertainties related to the use of a strip footing model with corrections due to shape and load conditions are not the focus. Hence, in order to enable a direct comparison with the capacity determined by the DNV approach, a rigid footing with width $b_{\text {eff }}=8 \mathrm{~m}$ is laid on the soil elements and a 2D model is applied. Eight-node plane strain elements with rectangular shape $(1 \mathrm{~m} \times 0.5 \mathrm{~m})$ are employed for the weightless soil. A Mohr-Coulomb elastic-perfectly plastic constitutive model is used for the soil elements. It should be noted that the Mohr-Coulomb criterion simplifies to the Tresca criterion under undrained conditions $(\phi=0)$. To avoid having yielded elements close to boundaries, the overall mesh dimensions are set to a width of $9 \cdot 5 b_{\text {eff }}$ and a depth of $2 b_{\text {eff }}$. The footing boundary is tied to the soil nodes implying a rough interface, so the soil cannot slide under the footing. Furthermore, a loadcontrolled method allowing foundation rotations is utilised within the FE analyses.

To obtain the same characteristic bearing capacity as the deterministic design, the FE model is calibrated with the material properties in Table 3. The calibration is performed by using deterministic properties and the characteristic value for the elastic modulus in Table 3 and changing the characteristic value for $c_{\mathrm{u}}$. Once the calibrated characteristic value for $c_{\mathrm{u}}$ is known, Table 3 can be used to obtain the calibrated distribution for the undrained shear strength with the considered coefficient of variation $(\mathrm{COV})$ in the $\mathrm{FE}$ model, $c_{\text {uFEM }}$.

Table 6 presents the characteristic values of the bearing capacities obtained by Abaqus. This value is close to the value from deterministic design (the DNV method). Results of the deterministic FE analyses are displayed in Fig. 2, which illustrates the failure mechanism in terms of the displacement vector field. The load-displacement curve for the deterministic analysis is presented in Fig. 3. As shown in this figure, the load-displacement curve meets the same bearing capacity as obtained using DNV.

\section{Generating the random field}

To create a probabilistic FE model, the undrained shear strength $c_{\mathrm{uFEM}}$ and the elastic modulus $E$ in Table 3 are modelled as cross-correlated random fields. A Markovian correlation function (equation (10)) is used for the random field. The correlation between points in the field is considered to decay exponentially with absolute distance between the points. In equation (10), $\Delta x$ and $\Delta y$ are spatial distances in the horizontal and vertical directions, respectively, and $\delta_{x}$ and $\delta_{y}$ are correlation lengths from Table 3. 


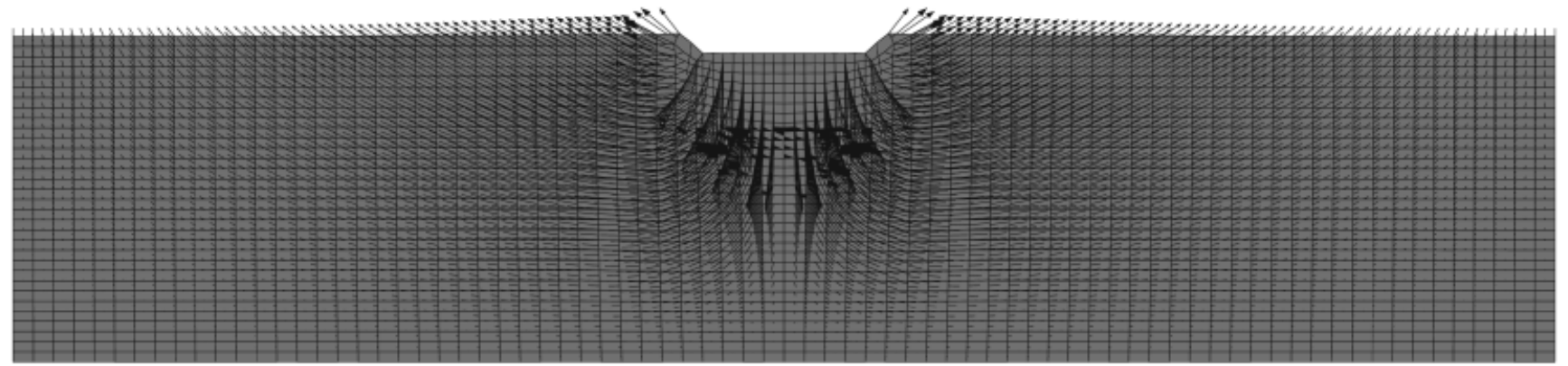

Fig. 2. An illustration of the failure mechanism using a displacement vector field in Abaqus

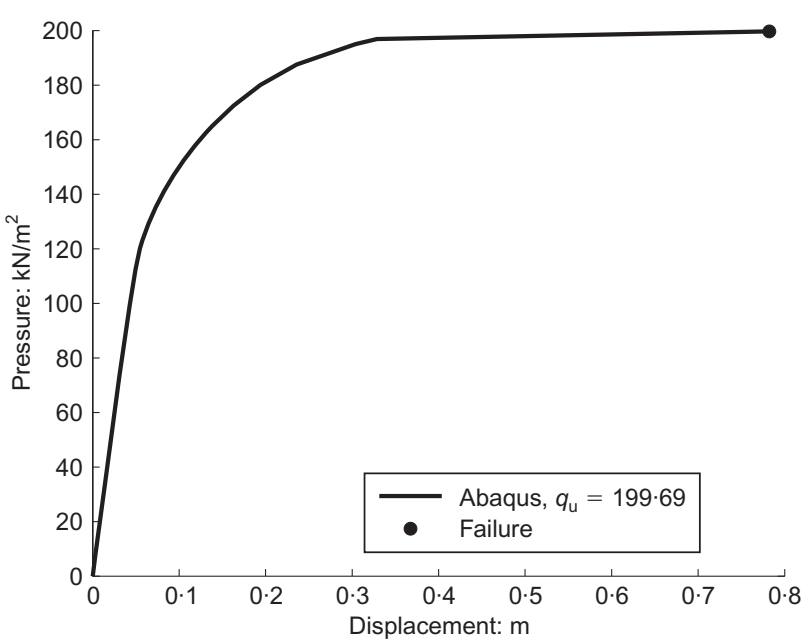

Fig. 3. Load-displacement curves for FE model in the deterministic design

$$
\rho_{\text {field }}=\exp \left[-2 \sqrt{\left(\frac{\Delta x}{\delta_{x}}\right)^{2}+\left(\frac{\Delta y}{\delta_{y}}\right)^{2}}\right]
$$

For the probabilistic FE model, random fields are generated with the matrix decomposition method. For each realisation, a vector of standard Gaussian random seeds, $U(x)$, the same size as the number of integration points, is generated for each random field. The correlation matrix $\tilde{R}$ is constructed with the correlation function specified in equation (10) and decomposed through equation (11a), where $\tilde{L}$ is the lower triangular matrix used for transferring $U(x)$ to the correlated field with zero mean $G(x)$, as in equation (11b).

$$
\begin{aligned}
& \tilde{L} \times \tilde{L}^{\mathrm{T}}=\tilde{R} \\
& G(x)=\tilde{L} \times U(x)
\end{aligned}
$$

Having the standard correlated random fields with zero mean, $G_{1}(x)=\left\{G_{1}\left(x_{1}\right), \ldots, G_{1}\left(x_{n}\right)\right\}$ for $c_{\mathrm{uFEM}}$ and $G_{2}(x)=$ $\left\{G_{2}\left(x_{1}\right), \ldots, G_{2}\left(x_{n}\right)\right\}$ for $E$ ( $n$ is number of integration points), cross-correlation between the two random fields can be applied as shown in equation (12)

$$
\left[\begin{array}{l}
G_{c}(x) \\
G_{E}(x)
\end{array}\right]=\left[\begin{array}{cc}
1 & 0 \\
\rho & \sqrt{1-\rho^{2}}
\end{array}\right] \times\left[\begin{array}{l}
G_{1}(x) \\
G_{2}(x)
\end{array}\right]
$$

where $G_{c}(x)$ and $G_{E}(x)$ are cross-correlated random fields with zero mean for $c_{\mathrm{uFEM}}$ and $E$, respectively. The multiplier matrix to random fields is the lower triangular matrix produced by the Cholesky decomposition on the crosscorrelation matrix, where $\rho$ is the cross-correlation between the random fields (see Table 3). Once the cross-correlated random fields from equation (12) are known for each random variable, transformation to the random fields with real distribution for $c_{\mathrm{uFEM}}$ and $E$ can be performed as

$$
\begin{aligned}
& Y_{c}=\exp \left(\mu_{\ln c_{\mathrm{uFEM}}}+\sigma_{\ln c_{\mathrm{uFEM}}} G_{c}\right) \\
& Y_{E}=\exp \left(\mu_{\ln E}+\sigma_{\ln E} G_{E}\right)
\end{aligned}
$$

where $\mu_{\ln c_{\mathrm{FFEM}}}$ and $\mu_{\ln E}$ are lognormal mean values for $c_{\mathrm{uFEM}}$ and $E$, respectively, and $\sigma_{\ln c_{\mathrm{uFEM}}}$ and $\sigma_{\ln E}$ are lognormal standard deviations for $c_{\mathrm{uFEM}}$ and $E$, respectively, from Table 3 .

To map the random field to the integration points in the Abaqus models, the procedure proposed by Vahdatirad et al. (2013) is applied. A user-defined material subroutine (UMAT) has been developed, in which the random material properties (random fields) are mapped as solution-dependent state variables (SDVs) in each integration point of the soil elements (see Abaqus (2011) and Clausen et al. (2007) for more details). Fig. 4 shows a sample of correlated random fields used in the Abaqus model. This figure presents the high positive correlation between undrained shear strength and elastic modulus as considered in Table 3.

Running the probabilistic FE models by MCS, numerous realisations for the bearing capacity can be obtained and used for the reliability analysis. Fig. 5 presents a sample of the deformed mesh at the failure step with the mapped random field for the undrained shear strength. Darker parts in this figure represent the stiffer areas with higher undrained shear strength, whereas lighter parts represent weaker zones with lower stiffness and strength. The footing may rotate in this model (see Fig. 5) due to presence of strength and

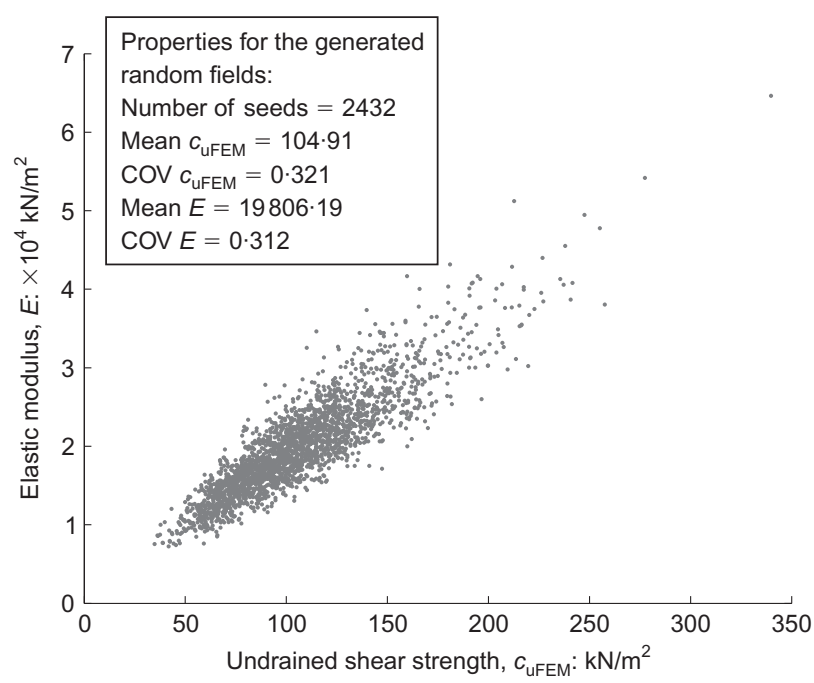

Fig. 4. A sample of cross-correlated integration point-mapped random fields using Cholesky decomposition method. Horizontal correlation length $=0 \cdot 5 b_{\text {eff }}$ 


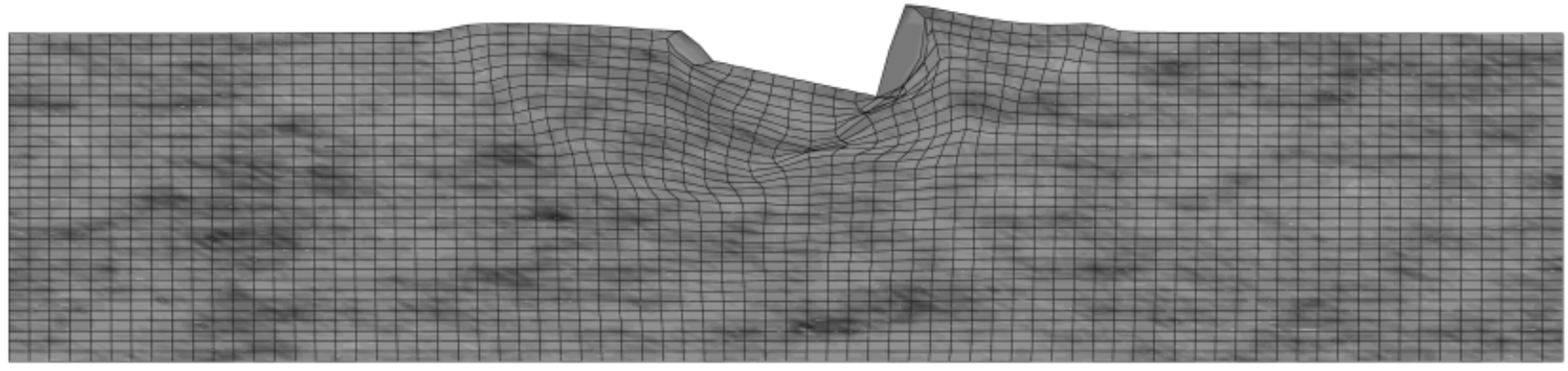

Fig. 5. Mapped random field for the undrained shear strength with a horizontal correlation length of $0 \cdot 5 b_{\text {eff }}$

stiffness variability and, as a result of this, differential settlement under the foundation.

Figure 6 illustrates a sample for the developed failure mechanism, presented by the displacement vectors. The random fields shown in Fig. 5 were also used in this realisation. As illustrated in Fig. 6, the failure mechanism differs significantly from that in a homogeneous soil (Fig. 2) because the failure mechanism is able to 'seek out' a path through the weaker parts of the soil.

\section{Model for the bearing capacity distribution and related uncertainties}

For each horizontal correlation length in Table 3, probabilistic models have been run by MCS, with 1000 realisations for each simulation. Using the realisations from MCS, the cumulative distribution function can be obtained and plotted (Fig. 7). A lognormal distribution, y, for the modelling of the bearing capacity can be considered using curve fitting. However, there can be uncertainty related to the choice of probability distribution type and the insufficiency of data for the distribution parameters. This model/statistical uncertainty can be estimated and added to the resistance part in the reliability analysis (see next section on 'Reliability analysis').

The lower tail of the resistance distribution is important in the reliability analysis; therefore, curve fitting is performed on samples at this tail (i.e. data points below the $5 \%$ quantile). To estimate uncertainties related to parameters of the fitted distribution, 'bootstrapping' is used (Efron \& Tibshirani, 1993). Original points at the lower tail of the lognormal distribution are resampled with bootstrapping and used for the new curve fitting. This process is repeated many (10 000) times. For the fitted distribution, $y$, parameters (i.e. lognormal mean value $\mu_{\ln y}$ and standard deviation $\sigma_{\ln y}$ ) are estimated for each resampled data set. Once the estimated parameters are obtained (10000 samples), the correlation between parameters and histograms for each of them can be determined. Uncertainties related to the fitting parameters

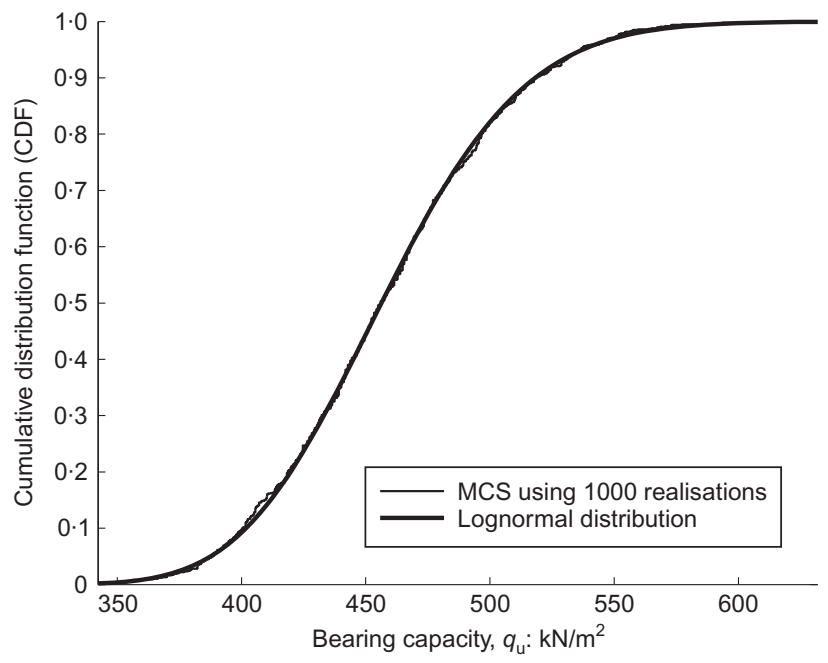

Fig. 7. CDF using MCS and fitted lognormal distribution as a model for bearing capacity. The horizontal correlation length of $b_{\text {eff }}$

are presented as normal distributions in each histogram. These distributions, together with the correlation between the estimated parameters, are added as uncertainties in the model for estimating the bearing capacities during reliability analysis (see next section on 'Reliability analysis').

In summary, the steps for estimating the statistical uncertainty of the fitted statistical parameters for the bearing capacity are as follows.

1. Identify data (points) in the lower tail of the bearing capacity distribution (i.e. $<5 \%$ quantile).

2. Create 10000 sets of resampled points using bootstrapping on the original samples from step 1 .

3. Fit a lognormal distribution to each set of bootstrapped samples in step 2. Find $\mu_{\ln y}$ and $\sigma_{\ln y}$. Perform curve fitting by the non-linear least-squares method.

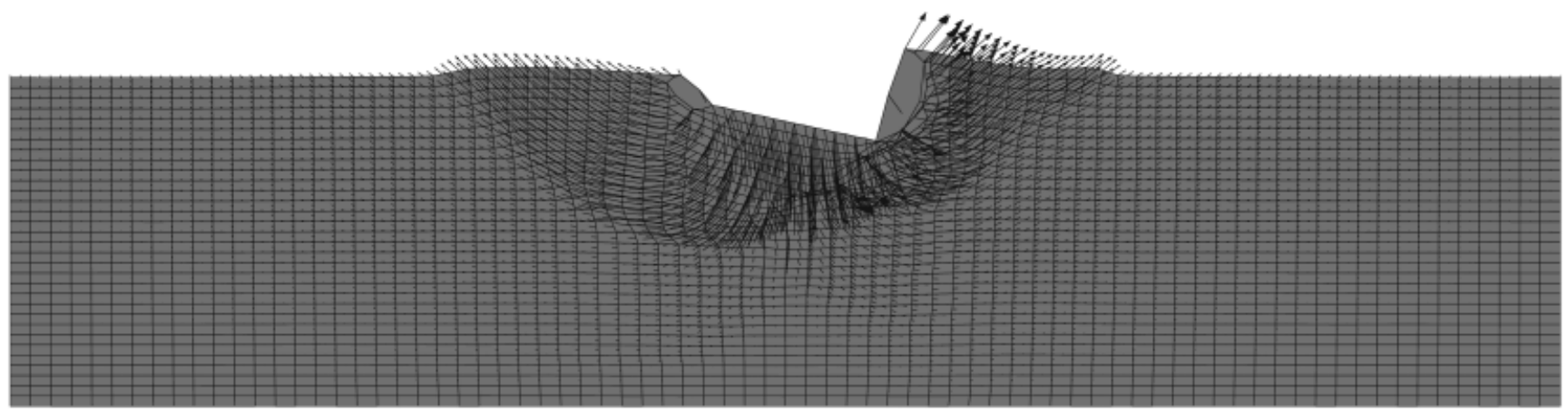

Fig. 6. An illustration of the failure mechanism for the same random field in Fig. 5 using a displacement vector field 
4. Estimate the correlation between samples of $\mu_{\ln y}$ and $\sigma_{\ln y}$ obtained from step 3.

5. Fit a normal distribution to the samples of $\mu_{\ln y}$ and $\sigma_{\ln y}$ obtained from step 3. Estimate the mean value and standard deviation of $\mu_{\ln y}$ and $\sigma_{\ln y}$.

Figure 8 shows the lognormal distribution fitted on one set of resampled points, which has been appropriately fitted with a high goodness of fit ( $R^{2}$ value). Fig. 9 illustrates an instance of fitted lognormal distributions for the entire resampling process. Figs 10 and 11 present the histograms and fitted normal distributions based on samples of $\mu_{\ln y}$ and $\sigma_{\ln y}$ obtained from the bootstrapping method. Table 7 presents the uncertainties related to the estimated lognormal parameters for the bearing capacity distribution (model) and the results for different horizontal correlation lengths.

\section{RELIABILITY ANALYSIS}

Once uncertainties for resistance $r$ and load $s$ are known, the generic form for the limit state function can be written as

$$
g=r-s
$$

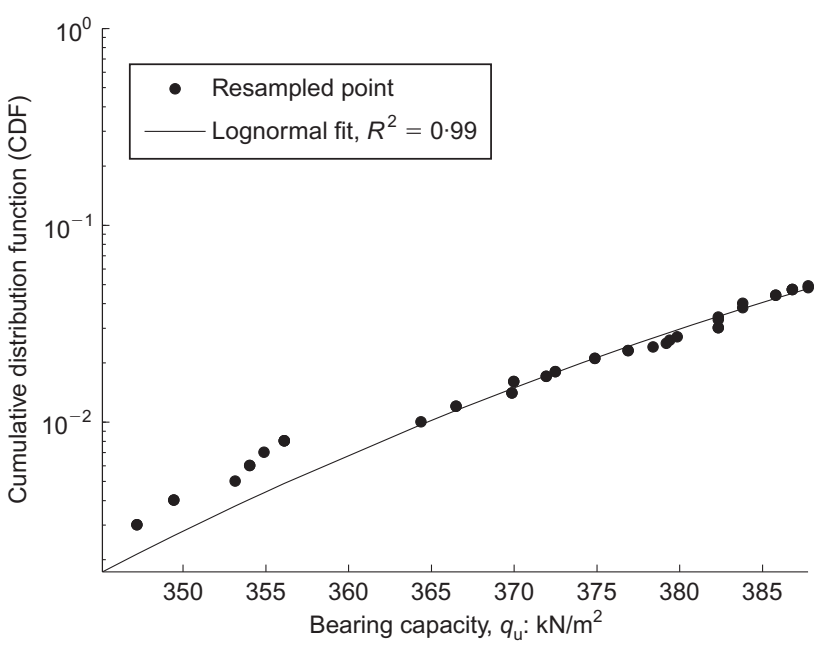

Fig. 8. Fitting a lognormal distribution to a set of resampled points at the tail of the distribution. The horizontal correlation length of $b_{\text {eff }}$

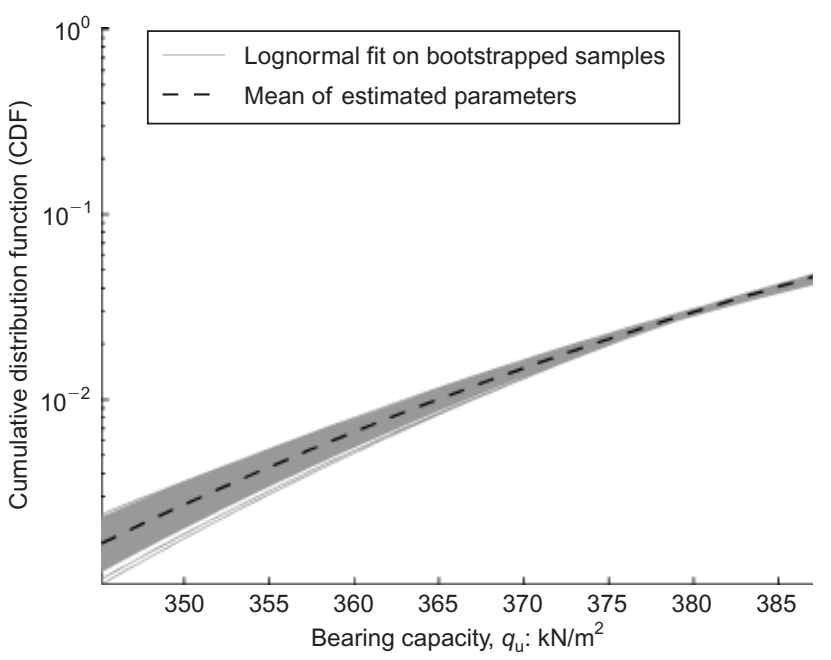

Fig. 9. Fitted lognormal distributions for the entire bootstrapping process using a resampling of 10000 . The horizontal correlation length of $b_{\text {eff }}$

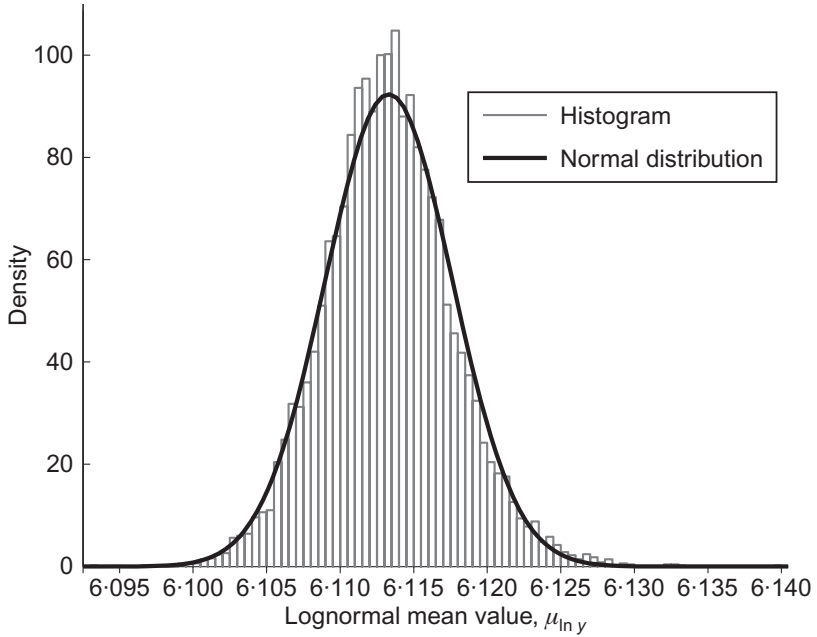

Fig. 10. Distribution for the lognormal mean value, $\mu_{\ln y}$, obtained from resampling. The horizontal correlation length of $b_{\text {eff }}$

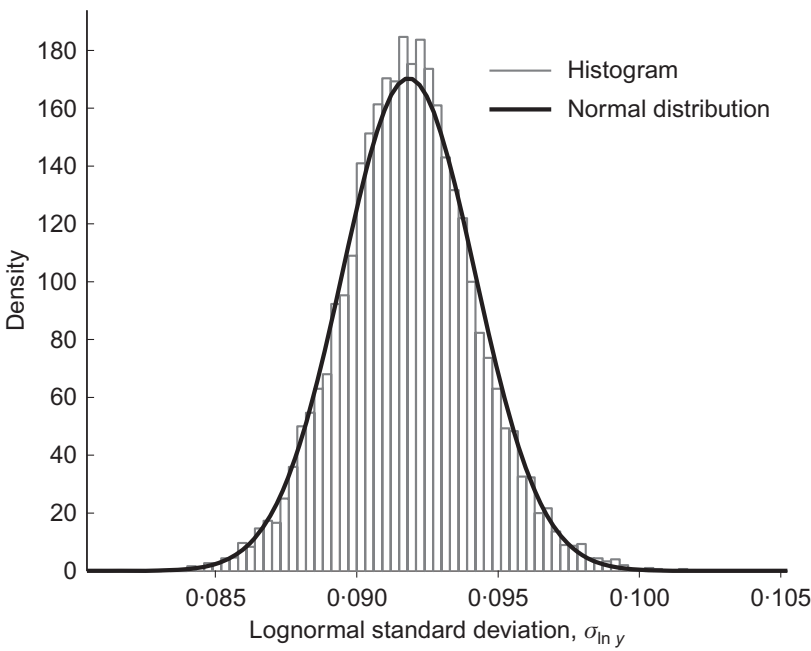

Fig. 11. Distribution for the lognormal standard deviation, $\sigma_{\ln y}$, obtained from resampling. The horizontal correlation length of $b_{\text {eff }}$

Positive values for $g$ correspond to the safety region with no failure; negative values represent the failure states. In order to account for uncertainties in the load (from Tables 2 and 5), a representative simple model for the wind turbine load is used (see, e.g. Sørensen \& Toft, 2010):

$$
s=X_{\mathrm{dyn}} X_{\exp } X_{\text {aero }} X_{\text {str }} H L
$$

where $X_{\text {dyn }}$ models the uncertainty for modelling the dynamic response, including uncertainty in damping ratios and natural frequencies; $X_{\exp }$ models the uncertainty related to modelling exposure, such as terrain roughness and landspace topography (i.e. uncertainties related to site assessment). Further, $X_{\text {aero }}$ models the uncertainty related to assessment of lift and drag coefficients; $X_{\text {str }}$ models the uncertainty related to computation of the load effects given external load; $H$ models the uncertainty related to the annual extreme load effect, due to wind load; and $L=85 \mathrm{~m}$ is the wind turbine height (Table 1). Considering uncertainties for the resistance part, $r$ can be expressed as shown in equation (16) (equivalent to the deterministic model in equation (9))

$$
r=\theta y A_{\mathrm{eff}} e
$$

where $\theta$ accounts for the model uncertainty from Table 5, $A_{\text {eff }}$ is the effective area of the foundation, $e$ is the load 
Table 7. Uncertainties related to the estimated lognormal parameters for the bearing capacity $\left(\mathrm{kN} / \mathrm{m}^{2}\right)$ using resampling method (bootstrapping)

\begin{tabular}{|c|c|c|c|c|c|}
\hline \multirow{2}{*}{$\begin{array}{l}\text { Horizontal } \\
\text { correlation } \\
\text { length }\end{array}$} & \multicolumn{2}{|c|}{$\begin{array}{l}\text { Uncertainty for the estimated lognormal } \\
\text { mean, } \mu_{\ln y}\end{array}$} & \multicolumn{2}{|c|}{$\begin{array}{l}\text { Uncertainty for the estimated lognormal standard } \\
\qquad \text { deviation, } \sigma_{\ln y}\end{array}$} & \multirow{2}{*}{$\begin{array}{c}\text { Correlation } \\
\text { between } \mu_{\ln y} \\
\text { and } \sigma_{\ln y}, \\
\rho_{\mu_{\ln y}, \sigma_{\ln y}}\end{array}$} \\
\hline & Mean value, $\mu_{\mu_{\ln y}}$ & Standard deviation, $\sigma_{\mu_{\ln y}}$ & Mean value, $\mu_{\sigma_{\ln y}}$ & Standard deviation, $\sigma_{\sigma_{\ln y}}$ & \\
\hline $\begin{array}{l}0 \cdot 5 b_{\text {eff }} \\
b_{\text {eff }} \\
2 b_{\text {eff }} \\
4 b_{\text {eff }} \\
8 b_{\text {eff }}\end{array}$ & $\begin{array}{l}6 \cdot 154 \\
6 \cdot 113 \\
6 \cdot 146 \\
6 \cdot 089 \\
6 \cdot 088\end{array}$ & $\begin{array}{l}0 \cdot 0039 \\
0 \cdot 0043 \\
0 \cdot 0026 \\
0 \cdot 0045 \\
0 \cdot 0070\end{array}$ & $\begin{array}{l}0 \cdot 092 \\
0 \cdot 092 \\
0 \cdot 130 \\
0 \cdot 117 \\
0 \cdot 111\end{array}$ & $\begin{array}{l}0 \cdot 0021 \\
0 \cdot 0023 \\
0 \cdot 0017 \\
0 \cdot 0025 \\
0 \cdot 0037\end{array}$ & $\begin{array}{l}0.997 \\
0.995 \\
0.991 \\
0.997 \\
0.997\end{array}$ \\
\hline
\end{tabular}

eccentricity (from Table 6), and $y$ is the model for estimating the bearing capacity, which contains the fitting uncertainty in the previous subsection on the 'Model for the bearing capacity distribution and related uncertainties'. Finally, considering the lognormal model and relevant uncertainties to estimate the bearing capacity from the same previous subsection, $y$ can be determined as

$$
y=h\left(q_{\mathrm{u}} \mid \mu_{\ln y}, \sigma_{\ln y}\right)
$$

where $h($.$) is the lognormal distribution, and \mu_{\ln y}$ and $\sigma_{\ln y}$ are the mean value and standard deviation, respectively, for the lognormal model $y$ from that subsection.

As the limit state equation $g$ is differentiable, the firstorder reliability method (FORM) (Hasofer \& Lind, 1974) can be used to find the exact value of the reliability index $\beta$. By normalising the stochastic variables in the bearing capacity in equation (17), this function can be written as

$$
y=\exp \left(\mu_{\ln y}+\sigma_{\ln y} X_{1}\right)
$$

in the normal space, where $X_{1}$ is the standard normal variable. As presented in the subsection on the 'Model for the bearing capacity distribution and related uncertainties', there are uncertainties related to $\mu_{\ln y}$ and $\sigma_{\ln y}$ that must be considered in the model shown in equation (18). As $\mu_{\ln y}$ and $\sigma_{\ln y}$ are correlated (see also Table 7), this correlation must be applied through the analysis. For this reason, the correlated random variables for $\mu_{\ln y}$ and $\sigma_{\ln y}$ can be determined from

$$
\left\{\begin{array}{l}
X_{\mu} \\
X_{\sigma}
\end{array}\right\}=\left[\begin{array}{ll}
1 & 0 \\
\rho_{\mu_{\ln y}, \sigma_{\ln y}} & \sqrt{1-\rho_{\mu_{\ln y}, \sigma_{\ln y}}^{2}}
\end{array}\right] \times\left\{\begin{array}{l}
X_{2} \\
X_{3}
\end{array}\right\}
$$

Here, $X_{2}$ and $X_{3}$ are realisations for the standard normal variables, $\rho_{\mu_{\ln v}, \sigma_{\ln y}}$ is the correlation between $\mu_{\ln y}$ and $\sigma_{\ln y}$ in Table 7 , and $X_{\mu}$ and $X_{\sigma}$ are correlated random variables for $\mu_{\ln y}$ and $\sigma_{\ln y}$, respectively. Because $\mu_{\ln y}$ and $\sigma_{\ln y}$ are assumed to be normally distributed (see 'Model for the bearing capacity distribution and related uncertainties'), $y$ in equation (18) becomes

$$
y=\exp \left[\left(\mu_{\mu_{\ln y}}+\sigma_{\mu_{\ln y}} X_{\mu}\right)+\left(\mu_{\sigma_{\ln y}}+\sigma_{\sigma_{\ln y}} X_{\sigma}\right) X_{1}\right]
$$

where $\mu_{\mu_{\ln y}}$ and $\sigma_{\mu_{\ln y}}$ are the mean value and standard deviation for the lognormal mean $\mu_{\ln y}$, respectively. Furthermore, $\mu_{\sigma_{\ln y}}$ and $\sigma_{\sigma_{\ln y}}$ are the mean value and standard deviation for the lognormal standard deviation $\sigma_{\ln y}$, respectively (cf. Table 7).

Once functions for the resistance part $r$ and the load part $s$ in the normal space are known, FORM can be implemented on the normalised limit state function $g$ through equation (14). Table 8 illustrates the results of the reliability analysis using FORM. For different stochastic FE models and different correlation lengths, this table presents the corresponding values for the annual reliability index $\beta$ and the design point $u^{*}$, which is the most probable failure point.

Figure 12 shows the trend of the annual reliability index with respect to the horizontal correlation length ratio, $\delta_{x} / b_{\text {eff }}$. The reliability index is seen to decrease rapidly for short correlation lengths, but is almost constant for long correlation lengths. Thus, the reliability index has an inverse proportionality with the field's correlation (i.e., a less correlated field has a larger reliability index).

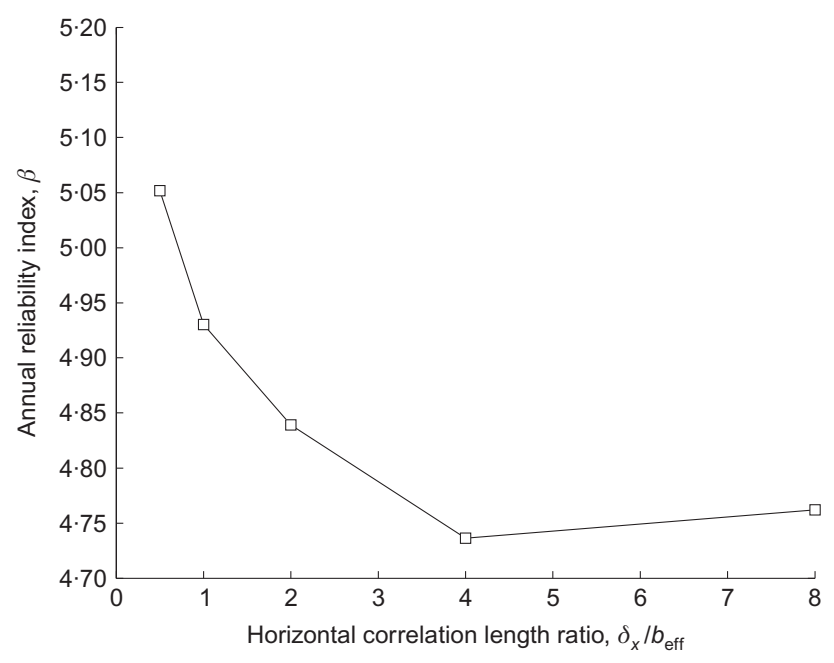

\begin{tabular}{|c|c|c|c|c|c|c|c|c|c|c|}
\hline \multirow[t]{2}{*}{$\delta_{x}: \mathrm{m}$} & \multicolumn{9}{|c|}{ Design point, $u^{*}$} & \multirow{2}{*}{$\begin{array}{r}\text { Annual } \\
\text { reliability } \\
\text { index, } \beta\end{array}$} \\
\hline & $\theta^{*}$ & $\mu_{\ln y}^{*}: \mathrm{kN} / \mathrm{m}^{2}$ & $\sigma_{\ln y}^{*}: \mathrm{kN} / \mathrm{m}^{2}$ & $q_{\mathrm{u}}^{*}: \mathrm{kN} / \mathrm{m}^{2}$ & $X_{\text {dyn }}^{*}$ & $X_{\exp }^{*}$ & $X_{\text {aero }}^{*}$ & $X_{\mathrm{str}}^{*}$ & $H^{*}: \mathrm{kN}$ & \\
\hline $0 \cdot 5 b_{\text {eff }}$ & $0 \cdot 853$ & $6 \cdot 154$ & $0 \cdot 092$ & 411.929 & $1 \cdot 038$ & $1 \cdot 803$ & $1 \cdot 364$ & $1 \cdot 161$ & $1.197 \times 10^{3}$ & $5 \cdot 052$ \\
\hline$b_{\text {eff }}$ & 0.855 & $6 \cdot 113$ & 0.092 & 397.457 & 1.037 & 1.780 & 1.345 & $1 \cdot 158$ & $1.195 \times 10^{3}$ & 4.930 \\
\hline $2 b_{\text {eff }}$ & $0 \cdot 862$ & $6 \cdot 146$ & $0 \cdot 130$ & $365 \cdot 608$ & 1.035 & 1.728 & $1 \cdot 149$ & $1 \cdot 130$ & $1.189 \times 10^{3}$ & $4 \cdot 839$ \\
\hline $4 b_{\text {eff }}$ & 0.862 & 6.089 & $0 \cdot 117$ & $361 \cdot 881$ & 1.035 & 1.725 & 1.294 & $1 \cdot 148$ & $1.188 \times 10^{3}$ & 4.736 \\
\hline $8 b_{\text {eff }}$ & $0 \cdot 861$ & $6 \cdot 088$ & $0 \cdot 111$ & 367.993 & 1.036 & 1.732 & $1 \cdot 306$ & $1 \cdot 149$ & $1.190 \times 10^{3}$ & $4 \cdot 762$ \\
\hline
\end{tabular}

Fig. 12. Annual reliability index plotted against horizontal correlation length ratio, $\delta_{x} / b_{\text {eff }}$

Table 8. Results for reliability analysis using FORM 
Interpreting biases in the model

Table 8 and Fig. 12 demonstrate that the estimated annual reliability indices were high $(>3-4)$ for bearing capacity problems in wind turbine foundations (IEC, 2005; DNV, 2013; Vahdatirad et al., 2013). These high values explain the existence of bias to estimate higher annual reliability indices in the model proposed by the DNV standard (calibrated FE model) for the deterministic design. It is noted that the target annual failure probability proposed by DNV is $10^{-4}$ (DNV, 2013), corresponding to an annual reliability index of $3 \cdot 72$. Bias could have strong contributions to the code-based design for conservative models and load-bearing capacity formulae, or when very conservative strength parameters (i.e. 5\% quantile) are chosen. Biases for the resistance part and for the strength parameter (i.e. undrained shear strength) have been interpreted in this study. Considering these biases, the design equation in equation (8) can be reformulated as

$$
\eta_{\mathrm{r}} \theta_{\mathrm{c}} q_{\mathrm{uc}}\left(\eta_{c_{\mathrm{u}}} \frac{c_{\mathrm{uc}}}{\gamma_{\mathrm{m}}}, w\right) A_{\mathrm{eff}} e-\gamma_{\mathrm{f}} H_{\mathrm{c}} L=0
$$

Here, $\eta_{r}$ and $\eta_{c_{u}}$ are biases for the resistance part and strength parameter, respectively, and $w$ represents other deterministic parameters in the FE model for the characteristic bearing capacity $q_{\mathrm{uc}}($.$) . Considering a pair of \left(\eta_{\mathrm{r}}, \eta_{c_{\mathrm{u}}}\right)$ and solving equation (21) for $H_{\mathrm{c}}$, a new distribution for the load $H$ can be obtained and used in the reliability analysis to determine the target reliability index. On the other hand $\left(\eta_{\mathrm{r}}, \eta_{c_{\mathrm{u}}}\right)$ are chosen to determine $H_{\mathrm{c}}$, such that the annual reliability index obtained by considered load distribution $H$ is equal to the target annual reliability index. An infinite number of pairs of $\left(\eta_{\mathrm{r}}, \eta_{c_{u}}\right)$ may satisfy the design equation for a considered value of $H_{\mathrm{c}}$ and give the same target reliability index. Fig. 13 presents an instance of the equal annual reliability index lines for the considered horizontal correlation length and limited ranges of $\eta_{\mathrm{r}}$ and $\eta_{c_{\mathrm{u}}}$. Values for $\eta_{\mathrm{r}}$ and $\eta_{c_{\mathrm{u}}}$ increase as the target reliability index decreases.

\section{Optimising the foundation radius}

The DNV method described in the deterministic design section has been utilised with the bias-reformulated design equation to obtain optimised values for foundation radii corresponding to a target annual reliability index. A pair of biases $\left(\eta_{\mathrm{r}}, \eta_{c_{\mathrm{u}}}\right)$ corresponding to a target annual reliability index has been chosen from the equal annual reliability

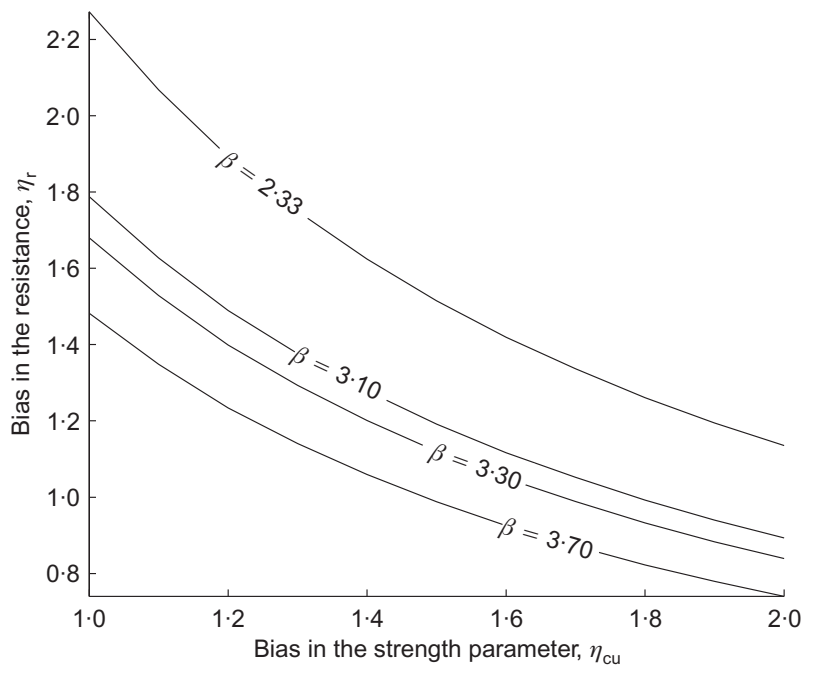

Fig. 13. Equal target annual reliability, $\beta$, curves for $\eta_{\mathrm{r}}$ and $\eta_{\mathrm{cu}}$. The horizontal correlation length of $b_{\text {eff }}$ index lines (e.g. Fig. 13) and applied as multipliers to the resistance part $Y_{\mathrm{d}}$ and strength parameter $c_{\mathrm{uc}}$ in equation (8). Consequently, a foundation radius $R_{\text {optim }}$ corresponding to the considered target annual reliability index is obtained. A single target annual reliability index results in several foundation radius values because different values of $\left(\eta_{\mathrm{r}}, \eta_{c_{\mathrm{u}}}\right)$ exist for one annual reliability index (cf. Fig. 13). To interpret the results, the ratio between the optimised value of the foundation radius $R_{\mathrm{optim}}$ and the radius $R_{\mathrm{DNV}}$ obtained from the no-bias situation $\left(\eta_{\mathrm{r}}=\eta_{c_{\mathrm{u}}}=1\right)$ is defined.

Figure 14 illustrates an instance of the relationship between the radius ratio $R_{\mathrm{optim}} / R_{\mathrm{DNV}}$ and the target annual reliability index $\beta$ in the range of considered biases. Differences between the maximum and minimum values for the $R_{\text {optim }} / R_{\text {DNV }}$ ratio are too small at each reliability level. Optimal combinations for $\eta_{\mathrm{r}}$ and $\eta_{c_{w}}$, which minimise the optimised foundation radius, are shown as solid lines in the figure. Table 9 and Fig. 15 present the minimum value for $R_{\text {optim }} / R_{\mathrm{DNV}}$ with respect to the annual reliability index at

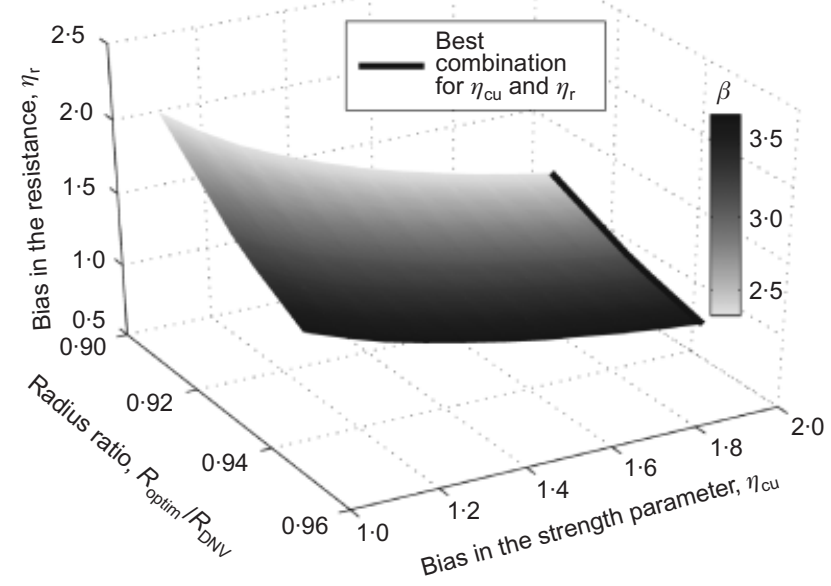

Fig. 14. Relation between optimum foundation radius, target annual reliability index, $\beta$, and biases. A horizontal correlation length of $b_{\text {eff }}$ is considered

Table 9. Foundation radius ratio for different target annual reliability indices

\begin{tabular}{|c|c|c|c|c|}
\hline \multirow[t]{2}{*}{$\delta_{x}: \mathrm{m}$} & \multirow{2}{*}{$\begin{array}{l}\text { Annual } \\
\text { reliability } \\
\text { index, } \beta\end{array}$} & \multicolumn{2}{|c|}{$\begin{array}{l}\text { Best combinations for the } \\
\text { biases }\end{array}$} & \multirow[t]{2}{*}{$\begin{array}{l}\text { Radius ratio, } \\
R_{\text {optim }} / R_{\mathrm{DNV}}\end{array}$} \\
\hline & & $\eta_{\mathrm{r}}$ & $\eta_{\mathrm{cu}}$ & \\
\hline \multirow[t]{4}{*}{$0 \cdot 5 b_{\text {eff }}$} & $2 \cdot 33$ & $1 \cdot 181$ & $2 \cdot 000$ & $0 \cdot 902$ \\
\hline & $3 \cdot 10$ & 0.929 & $2 \cdot 000$ & $0 \cdot 920$ \\
\hline & $3 \cdot 30$ & $0 \cdot 873$ & $2 \cdot 000$ & 0.926 \\
\hline & $3 \cdot 70$ & 0.770 & $2 \cdot 000$ & 0.938 \\
\hline \multirow[t]{4}{*}{$b_{\text {eff }}$} & $2 \cdot 33$ & $1 \cdot 135$ & $2 \cdot 000$ & 0.905 \\
\hline & $3 \cdot 10$ & 0.893 & $2 \cdot 000$ & 0.924 \\
\hline & $3 \cdot 30$ & $0 \cdot 839$ & $2 \cdot 000$ & 0.930 \\
\hline & $3 \cdot 70$ & $0 \cdot 740$ & $2 \cdot 000$ & 0.942 \\
\hline \multirow[t]{4}{*}{$2 b_{\text {eff }}$} & $2 \cdot 33$ & $1 \cdot 137$ & $2 \cdot 000$ & 0.905 \\
\hline & $3 \cdot 10$ & $0 \cdot 886$ & $2 \cdot 000$ & 0.925 \\
\hline & $3 \cdot 30$ & $0 \cdot 830$ & $2 \cdot 000$ & 0.931 \\
\hline & $3 \cdot 70$ & $0 \cdot 728$ & $2 \cdot 000$ & $0 \cdot 944$ \\
\hline \multirow[t]{4}{*}{$4 b_{\text {eff }}$} & $2 \cdot 33$ & $1 \cdot 086$ & $2 \cdot 000$ & 0.908 \\
\hline & $3 \cdot 10$ & $0 \cdot 849$ & $2 \cdot 000$ & $0 \cdot 929$ \\
\hline & $3 \cdot 30$ & 0.797 & $2 \cdot 000$ & 0.935 \\
\hline & $3 \cdot 70$ & $0 \cdot 700$ & $2 \cdot 000$ & $0 \cdot 948$ \\
\hline \multirow[t]{4}{*}{$8 b_{\text {eff }}$} & $2 \cdot 33$ & 1.090 & $2 \cdot 000$ & 0.908 \\
\hline & $3 \cdot 10$ & $0 \cdot 854$ & $2 \cdot 000$ & 0.928 \\
\hline & $3 \cdot 30$ & $0 \cdot 801$ & $2 \cdot 000$ & 0.934 \\
\hline & $3 \cdot 70$ & 0.705 & $2 \cdot 000$ & 0.948 \\
\hline
\end{tabular}




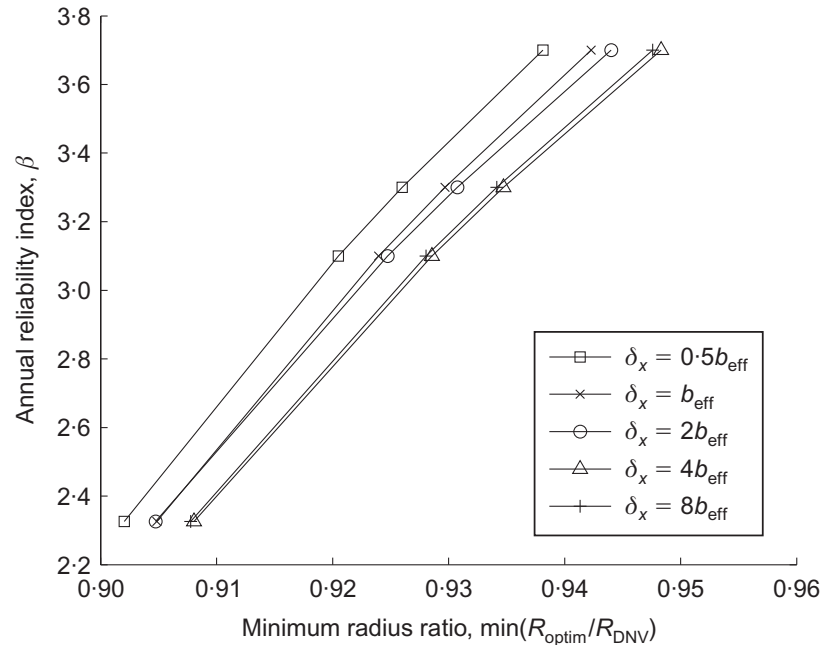

Fig. 15. Annual reliability index with respect to the minimum value of radius ratio obtained from the best combination of biases

different correlation lengths. The best choice for $\eta_{c_{u}}$ is always the maximum value in the considered range $\left(\eta_{c_{u}}=2\right)$ (Table 9). Thus, the global minimum for the optimised foundation radius might drop out of the considered range for $\eta_{\mathrm{r}}$ and $\eta_{c_{\mathrm{u}}}$

Theoretically, it would be interesting to find the global minimum for the optimised foundation radius. However, considering very large or very small biases may lead to unrealistic results due to errors in the FE modelling of the bearing capacity. On the other hand, changes in the optimised value for the foundation radius seem very small (see Fig. 14), such that the presented values in Table 9 are very close to the solutions. From the results in Table 9 and Fig. 15 , savings in the foundation radius of $5 \%$ to $10 \%$, depending on the target annual reliability index, are obtained by considering bias in the model. Apart from the cost of installation and transportation, considering a direct relationship between the volume of the material and the foundation radius squared, these results roughly corresponded to 10 $20 \%$ savings in material consumption, which is significant regarding the total cost of the foundation.

\section{CONCLUSION}

A code-based method for design of a gravity-based foundation has been assessed with focus on the reliability level regarding bearing capacity. In this context, a footing on undrained cohesive soil has been analysed. The random finite-element method (RFEM) has been used to perform the probabilistic modelling. The Monte Carlo simulations were complemented by a re-sampling technique, which focused on samples at the tail of the bearing capacity distribution. It has been shown that the reliability index decays with increasing correlation length. Furthermore, it has been found that the code-based design method overestimates failure probability. To perform more realistic and less conservative design, biases in the strength parameter and total resistance have been re-interpreted and used to calibrate the design equation. Optimal bias values are proposed to achieve acceptable target reliability indices. Optimised results using the calibrated design equation allow savings in material consumption of up to $20 \%$, depending on the target annual reliability level.

\section{ACKNOWLEDGEMENT}

The authors gratefully acknowledge financial support from the Danish Council for Strategic Research within the programme 'Reliability-based analysis applied for reduction of cost of energy for offshore wind turbines'.

\section{NOTATION}

$A_{\text {eff }}$ foundation effective area

$b_{\text {eff }}$ foundation effective width

$c_{\mathrm{u}}$ undrained shear strength used in DNV method

$c_{\mathrm{uc}}$ characteristic value for undrained shear strength

$c_{\mathrm{uFEM}}$ calibrated undrained shear strength used in FE models

$E$ soil elastic modulus

$e$ load eccentricity

$G(x)$ correlated random field with zero mean

$G_{c}(x)$ cross-correlated random fields with zero mean for $c_{\mathrm{uFEM}}$

$G_{E}(x)$ cross-correlated random fields with zero mean for $E$

$g$ limit state function

$H$ horizontal load at foundation base

$H_{\mathrm{c}} \quad$ characteristic value for horizontal load $H$

$h($.) lognormal distribution

$i^{0}$ inclination factor

$\stackrel{L}{L}$ height of wind turbine from foundation base

$\tilde{L} \quad$ lower triangular matrix

$l_{\text {eff }}$ foundation effective length

$M$ bending moment

$N_{c}^{0} \quad$ bearing capacity factor

$p_{0}$ effective overburden pressure

$q_{\mathrm{u}}$ bearing capacity

$q_{\mathrm{uc}}$ characteristic value for bearing capacity

$q_{\mathrm{uc}}($.$) FE model for the characteristic bearing capacity$

$R$ foundation radius

$R_{\mathrm{DNV}}$ design value for foundation radius obtained from DNV at the no-bias situation

$R_{\text {optim }}$ optimum foundation radius corresponding to target annual reliability

$\tilde{R}$ correlation matrix

$r$ resistance part in limit state function

$s$ load part in limit state function

$s_{c}^{0} \quad$ shape factor

$U(x)$ standard Gaussian random seeds

$V$ vertical load

$w$ deterministic parameters in FE model $q_{\mathrm{uc}}($.

$X_{1}$ standard normal variable

$X_{2}$ standard normal variable

$X_{3}$ standard normal variable

$X_{\text {aero }}$ uncertainty for assessment of lift and drag coefficients

$X_{\text {dyn }}$ uncertainty for modelling dynamic response

$X_{\exp }$ uncertainty for modelling exposure

$X_{\text {str }}$ uncertainty for computation of load effects given external load

$X_{\mu} \quad$ correlated random variable for $\mu_{\ln y}$ in normal space

$X_{\sigma}$ correlated random variable for $\sigma_{\ln y}$ in normal space

$Y_{c}$ random field with real distribution for $c_{\mathrm{uFEM}}$

$Y_{\mathrm{d}}$ characteristic value for resistance part in design equation

$Y_{E}$ random field with real distribution for $E$

$y$ fitted lognormal distribution to bearing capacity

$\beta$ annual reliability index

$\Delta x$ horizontal spatial distance

$\Delta y$ vertical spatial distance

$\delta_{x}$ horizontal correlation length

$\delta_{y} \quad$ vertical correlation length

$\gamma_{\mathrm{f}}$ partial safety factor for load

$\gamma_{\mathrm{m}}$ partial safety factor for material

$\eta_{c_{u}}$ bias for strength parameter

$\begin{array}{cll}\eta_{\mathrm{r}} & \text { biases for resistance part }\end{array}$

$\theta$ model uncertainty

$\theta_{c} \quad$ characteristic value of model uncertainty for bearing capacity

$\mu_{\ln c_{\mathrm{uFEM}}} \operatorname{lognormal}$ mean value for $c_{\mathrm{uFEM}}$

$\mu_{\ln E} \quad \operatorname{lognormal}$ mean value for $E$

$\mu_{\ln y}$ lognormal mean value for $y$

$\mu_{\mu_{\mathrm{n}}}$ mean value for $\mu_{\ln y}$

$\mu_{\sigma_{\ln y}} \quad$ mean value for $\sigma_{\ln y}$ 
$\rho$ cross correlation

$\rho_{\text {field }}$ correlation function

$\rho_{\mu_{\ln y}, \sigma_{\ln y}}$ correlation between $\mu_{\ln y}$ and $\sigma_{\ln y}$

$\sigma_{\ln c_{\mathrm{uFEM}}}$ lognormal standard deviation for $c_{\mathrm{uFEM}}$

$\sigma_{\ln E}$ lognormal standard deviation for $E$

$\sigma_{\ln y}$ lognormal standard deviation for $y$

$\sigma_{\mu_{\ln y}} \quad$ standard deviation for $\mu_{\ln y}$

$\sigma_{\sigma_{\ln y}}$ standard deviation for $\sigma_{\ln y}$

$\phi \quad$ soil friction angle

\section{REFERENCES}

Abaqus (2011). Section 1.1.17: Define initial solution-dependent state variable fields; Section 1.1.40: Define a material's mechanical behavior. In Abaqus user subroutine reference manual. Paris, France: Dassault Systèmes Simulia Corp.

Andersen, L. V., Vahdatirad, M. J. \& Sørensen, J. D. (2011). Reliability-based assessment of the natural frequency of an offshore wind turbine founded on a monopile. In Proceedings of 13th international conference on civil, structural and environmental engineering computing (eds B. H. V. Topping and Y. Tsompanakis), paper 83. Stirlingshire, Scotland: Civil-Comp Press.

Andersen, L. V., Vahdatirad, M. J., Sichani, M. T. \& Sørensen, J. D. (2012). Natural frequencies of wind turbines on monopile foundations in clayey soils: a probabilistic approach. Comput. Geotech. 43, 1-11.

BSI (2004). BS EN 1997-1: Eurocode 7: Geotechnical design Part 1: General rules. BSI, London, UK.

Cassidy, M. J., Uzielli, M. \& Tian, Y. (2013). Probabilistic combined loading failure envelopes of a strip footing on spatially variable soil. Comput. Geotech. 49, 191-205.

Clausen, J., Damkilde, L. \& Andersen, L. V. (2007). An efficient return algorithm for non-associated plasticity with linear yield criteria in principal stress space. Comput. Structs 85, No. 23-24, 1795-1807.

Dassault Systèmes Simulia Corp (2012). Abaqus 6.12 analysis user's manual. Providence, RI, USA: Dassault Systèmes Simulia Corp.

DNV (Det Norske Veritas) (2013). DNV-OS-J101: Offshore standard: design of offshore wind turbine structures. DNV, Oslo, Norway.

Efron, B. \& Tibshirani, R. (1993). An introduction to the bootstrap. Boca Raton, FL, USA: CRC Press.

European Wind Energy Association (2009). Wind energy - the facts: A guide to the technology, economics and future of wind power, pp. 212-218. London, UK: Earthscan.

Fenton, G. A. \& Griffiths, D. V. (2003). Bearing capacity prediction of spatially random $c-\phi$ soils. Can. Geotech. J. 40, No. 1, 54-65.

Fenton, G. A. \& Griffiths, D. V. (2005). Three-dimensional probabilistic foundation settlement. J. Geotech. Geoenviron. Engng, ASCE 131, No. 2, 232-239.

Fenton, G. A., Griffiths, D. V. \& Cavers, W. (2005). Resistance factors for settlement design. Can. Geotech. J. 42, No. 5, 1422-1436.

Fenton, G. A., Zhang, X. \& Griffiths, D. V. (2007). Reliability of shallow foundations designed against bearing failure using LRFD. Georisk: Assessment Mgmt Risk Engd Systems Geohazards 1, No. 4, 202-215, http://dx.doi.org/10.1080/ 17499510701812844.

Fenton, G. A., Griffiths, D. V. \& Zhang, X. (2008). Load and resistance factor design of shallow foundations against bearing failure. Can. Geotech. J. 45, No. 11, 1556-1571.

Griffiths, D. V. \& Fenton, G. A. (2000). Bearing capacity of heterogeneous soils by finite elements. In Proceedings of the 5th international congress on numerical methods in engineering and scientific applications (eds N. Troyani and M. Cerrolaza), pp. 27-37. Caracas, Venezuela: Sociedad Venezolana de Métodos Numéricos en Ingeniería.

Griffiths, D. V. \& Fenton, G. A. (2001). Bearing capacity of spatially random soil: the undrained clay Prandtl problem revisited. Géotechnique 51, No. 4, 351-359, http://dx.doi.org/ 10.1680/geot.2001.51.4.351.

Griffiths, D. V. \& Fenton, G. A. (2009). Probabilistic settlement analysis by stochastic and random finite-element methods. J. Geotech. Geoenviron. Engng, ASCE 135, No. 11, 1629-1637.

Griffiths, D. V., Fenton, G. A. \& Manoharan, N. (2002). Bearing capacity of rough rigid strip footing on cohesive soil: probabilistic study. J. Geotech. Geoenviron. Engng, ASCE 128, No. 9, $743-755$.

Griffiths, D. V., Fenton, G. A. \& Manoharan, N. (2006). Undrained bearing capacity of two-strip footings on spatially random soil. Int. J. Geomech., ASCE 6, No. 6, 421-427.

Hasofer, A. M. \& Lind, N. C. (1974). An exact and invariant first order reliability format. J. Engng Mech. Div., ASCE, 100, No. 1, 111-121.

IEC (International Electrotechnical Commission) (2005). IEC 61400-1: Wind turbines - Part 1: Design requirements, 3rd edn. Geneva, Switzerland: IEC.

JCSS (Joint Committee on Structural Safety) (2006). JCSS-Cl: probabilistic model code. Section 3.7: Soil properties, revised version. Technical University of Denmark, Denmark: Joint Committee on Structural Safety.

Lee, I. K., White, W. \& Ingles, O. G. (1983). Geotechnical engineering. London, UK: Pitman.

Nilsen, P. (2003). Offshore wind energy projects feasibility study guidelines SEAWIND, Altener project 4, 1030/Z/01-103/2001. Aalborg, Denmark: Energi- og Miljødata.

Paice, G. M. \& Griffiths, D. V. (1999). Bearing capacity reliability of an undrained clay block formed from spatially random soil. In Proceedings of 7 th conference on association of computational mechanics in engineering (ACME) (ed. P. Bettess), pp. 203-206. Sunderland, UK: Penshaw Press.

Phoon, K. K. (ed.) (2008). Reliability-based design in geotechnical engineering: Computations and applications. Oxford, UK: Taylor \& Francis.

Popescu, R., Deodatis, G. \& Nobahar, A. (2005). Effects of random heterogeneity of soil properties on bearing capacity. Probabilistic Engng Mech. 20, No. 4, 324-341.

Randolph, M. F., Jamiolkowski, M. B. \& Zdravkovic, L. (2004). Load carrying capacity of foundations. In Proceedings of Skempton memorial conference, London, vol. 1, pp. 207-240. London, UK: Thomas Telford.

Sørensen, J. D. (2013). Reliability assessment of wind turbines. Proceedings of European Safety and Reliability Association (ESREL) conference, Amsterdam (eds R. D. J. M. Steenbergen, P. H. A. J. M. van Gelder, S. Miraglia and A. C. W. M. Vrouwenvelder). London, UK: CRC Press.

Sørensen, J. D. \& Toft, H. S. (2010). Probabilistic design of wind turbines. Energies 3, No. 2, 241-257, http://dx.doi.org/10.3390/ en3020241.

Vahdatirad, M. J., Andersen, L. V., Clausen, J. \& Sørensen, J. D. (2011). The dynamic stiffness of surface footings for offshore wind turbines: reliability based assessment. In Proceedings of 13th international conference on civil, structural and environmental engineering computing (eds B. H. V. Topping and Y. Tsompanakis), paper 82. Stirlingshire, Scotland, UK: Civil-Comp Press.

Vahdatirad, M. J., Andersen, L. V., Ibsen, L. B., Clausen, J. \& Sørensen, J. D. (2013). Probabilistic three-dimensional model of an offshore monopile foundation: reliability based approach. In Proceedings of 7th international conference on case stories in geotechnical engineering: and symposium in honor of Clyde Baker (ed. S. Prakash), Missouri University of Science and Technology, paper 8.09a. Chicago, IL, USA: Missouri University of Science and Technology.

Vahdatirad, M. J., Bayat, M., Andersen, L. V. \& Ibsen, L. B. (2014). Probabilistic finite element stiffness of a laterally loaded monopile based on an improved asymptotic sampling method. J. Civ. Engng Manage, in press. 